\title{
Dependence Potential of Tramadol: Behavioral Pharmacology in Rodents
}

\author{
Hye Jin Cha ${ }^{1,3}$, Min Ji Song', Kwang-Wook Lee', Eun Jung Kim', Young-Hoon Kim¹, Yunje Lee', \\ Won-Keun Seong ${ }^{1}$, Sa-Ik Hong ${ }^{2}$, Choon-Gon Jang ${ }^{2}$, Han Sang Yoo ${ }^{3}$ and Ho-Sang Jeong ${ }^{1, *}$ \\ ${ }^{1}$ Pharmacological Research Division, Toxicological Evaluation and Research Department, National Institute of Food and Drug Safety \\ Evaluation, Ministry of Food and Drug Safety, Chungju 361-709, \\ ${ }^{2}$ School of Pharmacy, Sungkyunkwan University, Suwon 440-746, \\ ${ }^{3}$ Department of Infectious Diseases, College of Veterinary Medicine, Seoul National University, Seoul 151-742, Republic of Korea
}

\begin{abstract}
Tramadol is an opioid analgesic agent that has been the subject of a series of case reports suggesting potential for misuse or abuse. However, it is not a controlled substance and is not generally considered addictive in Korea. In this study, we examined the dependence potential and abuse liability of tramadol as well as its effect on the dopaminergic and serotonergic systems in rodents. In animal behavioral tests, tramadol did not show any positive effects on the experimental animals in climbing, jumping, and head twitch tests. However, in the conditioned place preference and self-administration tests, the experimental animals showed significant positive responses. Taken together, tramadol affected the neurological systems related to abuse liability and has the potential to lead psychological dependence.
\end{abstract}

Key Words: Tramadol, Dopamine system, Serotonin system, Drug dependence, Animal behavioral tests

\section{INTRODUCTION}

Tramadol is one of the most frequently prescribed drugs for moderate to severe pain in Korea. It is an atypical, centrally acting, synthetic analgesic functioning through opioid and non-opioid systems (Sarkar et al., 2012). It was first introduced in Germany in the late 1970s, and has been used widely around world. Several case reports have indicated the abuse potential of the drug (Nebhinani et al., 2013; Zhang and Liu, 2013; Randall and Crane, 2014), and it is controlled as a psychotropic substance in several countries including Australia, Sweden and some states in the USA. However, in most countries including Korea the drug is not controlled and even can be purchased without prescription in some countries. Besides, there are only a few scientific reports revealing its mechanism of action and dependence or abuse liability.

Drug dependence is defined as the loss of control over drug use or the compulsive seeking and taking of drugs despite adverse consequences (Koob, 1999). Animal experiment are an effective tool to indirectly evaluate drug dependence that is either physical or psychological (Acheson et al., 1999; Varlinskaya and Spear, 2002; Doremus et al., 2003; Chung et al, 2008; Morris et al., 2010). Physical dependence refers to chronic use of a drug to the point of tolerance in which negative physical symptoms or withdrawal result from abrupt drug discontinuation or dosage reduction (Landry et al., 1992). Psychological dependence refers to a lack of self restraint regarding drug use. Two important concepts pertaining to this phenomenon are reinforcement and reward (Taylor, 2002). "Reinforcement" refers to an event that increases the probability of a given action. The meaning of "reward" is similar, but reward usually refers to a positive sensation, such as pleasure (Koob, 1992).

Several laboratory experiments are commonly used to validate a drug's dependence potential (Chung et al., 2008). Researchers examine the climbing and head twitch behaviors in pre-evaluation experiments to monitor drug's dopaminergic and serotonergic effects, respectively. The jumping behavior test is typically used to determine a drug's potential to lead to physical dependence, particularly for the opioids (Way et al.,

\section{Open Access http://dx.doi.org/10.4062/biomolther.2014.064}

This is an Open Access article distributed under the terms of the Creative Commons Attribution Non-Commercial License (http://creativecommons.org/licenses/by-nc/3.0/) which permits unrestricted non-commercial use, distribution, and reproduction in any medium, provided the original work is properly cited.
Received May 29, 2014 Revised Jun 10, 2014 Accepted Jun 30, 2014 Published online Nov 30, 2014

*Corresponding Author

E-mail: hosa33@korea.kr

Tel: +82-43-719-5253, Fax: +82-43-719-5200 
1969; Saelens et al., 1971; Smits, 1975; Ritzmann, 1981; ElKadi and Sharif, 1994; Kest et al., 2001). Researchers make considerable use of the conditioned place preference test and self-administration test to investigate the substance's rewarding effect and reinforcing effect. The tests are commonly hired to evaluate and validate a substance's potential to result in psychological dependence in previous reports (Mucha et al., 1982; Gorelick et al., 2004).

In the present study, various animal behavioral tests including climbing, jumping, head-twitch, conditioned place preference and self-administration tests were conducted to evaluate the dependence potential of tramadol using experimental rodents.

\section{MATERIALS AND METHODS}

\section{Animals and drugs}

Sprague-Dawley rats (weight, 180-220 g) and ICR mice (weight, 15-20 g) were obtained from Korea Food and Drug Administration (AAALAC member, Seoul, Korea) and they were housed in groups, of adequate size, in a temperaturecontrolled $23 \pm 2^{\circ} \mathrm{C}$ room with a 12 hour light/dark cycle (lights on 08:00 to 20:00). The animal tests were approved by NIFDS/ KFDA Animal Ethics Board (0904KFDA053). The animals received a solid diet and tap water ad libitum, and their treatment conformed to the Guide for the Care and Use of Laboratory Animals (NRC 1996). We performed all experiments between 09:00 and 18:00. Methamphetamine $\mathrm{HCl}$, cocaine, and tramadol were obtained from Sigma (St. Louis, MO, USA).

\section{Apparatus}

The climbing behavior test apparatus was a stainless steel cylinder with many vertical bars that the experimental mice could climb. Its floor diameter was $12 \mathrm{~cm}$, and each vertical bar's length was $24 \mathrm{~cm}$. To evaluate jumping behavior and head twitch responses, a transparent box without ceiling measuring $30 \times 30 \times 40 \mathrm{~cm}$ was used.

The conditioned place preference test chamber had three distinct compartments (white, black, and gray) separated by automatic guillotine doors. Infrared photo-beam detectors were added for automated data collection. The overall inside dimensions were $21 \times 21 \times 68 \mathrm{~cm}$, and the unit's base measured $86.4 \times 25.4 \mathrm{~cm}$. The manufacturer provided the mounting holes for the ENV-013 IR Infrared Sensor Package (Med Associates Inc., St Albans, VT, USA), which places six photobeams across white and black zones, $1.25 \mathrm{~cm}$ from each end wall, with $5 \mathrm{~cm}$ intervals between the beams. The choice compartments were $28 \mathrm{~cm}$ long. One choice compartment was all black, with a stainless steel grid rod floor consisting of $4.8 \mathrm{~mm}$ rods on $16 \mathrm{~mm}$ centers. The other compartment was all white with a $1.25 \times 1.25 \mathrm{~cm}$ stainless steel mesh floor.

The self-administration test chamber was purchased from Med Associates Inc. and measured $29 \times 21 \times 24 \mathrm{~cm}$. The chambers contained two levers, an active lever to deliver a drug dose, via the jugular vein, through a connected catheter and an inactive lever, not connected to the experimental animal. Infusion pumps were placed outside the chamber and connected to a $10 \mathrm{ml}$ syringe. We connected the chamber to a computer, to record test data and control the experimental processes.

\section{Methods}

Climbing behavior test: One group of mice was administered the negative control (saline, $1 \mathrm{mg} / \mathrm{kg}$, intraperitoneally [i.p.]) or one of the three doses of tramadol $(0.03,0.07$, or 0.1 $\mathrm{mg} / \mathrm{kg}$, i.p.) for 40-90 min, respectively. Then for $1 \mathrm{~min}$, climbing duration of the mice was observed using a stopwatch. The other group of mice was pre-treated with the negative control (saline, $1 \mathrm{mg} / \mathrm{kg}$, i.p.) or one of the three doses of tramadol $(0.03,0.07$, or $0.1 \mathrm{mg} / \mathrm{kg}$, i.p.) for $40-90 \mathrm{~min}$ before the test. Then just before testing, apomorphine ( $2 \mathrm{mg} / \mathrm{kg}$, i.p.) was administered to each subject and their climbing duration was timed as above. The tests were repeated three times, with a time-out period of $10 \mathrm{~min}$.

Jumping test: One group of mice was administered the negative control (saline, $1 \mathrm{mg} / \mathrm{kg}$, i.p.), or one of the three doses of tramadol $(0.03,0.07$, or $0.1 \mathrm{mg} / \mathrm{kg}$, i.p.) for $40-90 \mathrm{~min}$ followed by naloxone (10 mg/kg, i.p.). Then for $15 \mathrm{~min}$, the jumping numbers of the animals were counted. The other group of mice was pre-treated with the negative control (saline, $1 \mathrm{mg} /$ $\mathrm{kg}$, i.p.) or one of the three doses of tramadol $(0.03,0.07$, or $0.1 \mathrm{mg} / \mathrm{kg}$, i.p.) for $40-90 \mathrm{~min}$ before the test. Next, morphine (150 mg/kg, s.c.) was administered followed by naloxone administration (10 $\mathrm{mg} / \mathrm{kg}$, i.p.) $4 \mathrm{hr}$ after the morphine treatment. The jumping number was counted for $15 \mathrm{~min}$. This experiment was repeated three times.

Head twitch response: One group of mice was administered the negative control (saline, $1 \mathrm{mg} / \mathrm{kg}$, intracerebroventricularly [i.c.v.]) and one of the three doses of tramadol (0.01, 0.03 , or $0.07 \mathrm{mg} / \mathrm{kg}$, i.p.) for $40-90 \mathrm{~min}$ before the test, and the numbers of head twitches were counted for $2 \mathrm{~min}$. The other group of mice was pre-treated with the negative control (saline, $1 \mathrm{mg} / \mathrm{kg}$, i.p.) and one of the three doses of tramadol $(0.01,0.03$, or $0.07 \mathrm{mg} / \mathrm{kg}$, i.p.) for $40-90 \mathrm{~min}$ before the test. Then 5-hydroxytryptamine (5-HT) (3-4 mg/kg, i.c.v.) was administered and the numbers of head twitches were counted for $2 \mathrm{~min}$. The test was repeated three times at $10 \mathrm{~min}$ intervals.

Conditioned place preference test: The mice were acclimated to the experimental apparatus and handled for 6 days before starting this experiment. The procedure was similar to that described previously (Bozarth, 1987; Narita et al., 2004).

Each experiment consisted of three phases, as follows.

Pre-conditioning: For 2 days (days 1 and 2) the rats were allowed free access to both compartments of the apparatus for $15 \mathrm{~min}(900 \mathrm{~s})$ each day. One day 2 , the time spent by the mice in each compartment was recorded and served as baseline. Mice showing preference for the black compartment were selected for further experiments and divided into two groups.

Conditioning: Conditioning was conducted for 8 days (days 3-10), one session per day. On day 3 , one group of the selected mice was treated with drugs (methamphetamine, $1 \mathrm{mg} /$ $\mathrm{kg}$, i.p., one of the three doses of tramadol, 0.5, 1.47, and $2.94 \mathrm{mg} / \mathrm{kg}$, i.p.), and placed in the non-preferred compartment (white) for $30 \mathrm{~min}$. The other group of mice was treated with saline, and placed in the preferred compartment (black) for $30 \mathrm{~min}$. The groups were switched every day, so that the drug was injected every other day, and the same procedure was conducted.

Post-conditioning: On day 11, the mice were allowed free access to both compartments of the apparatus for 15 min (900 s). The time spent by the mice in each compartment was recorded, and these values were the test line. 


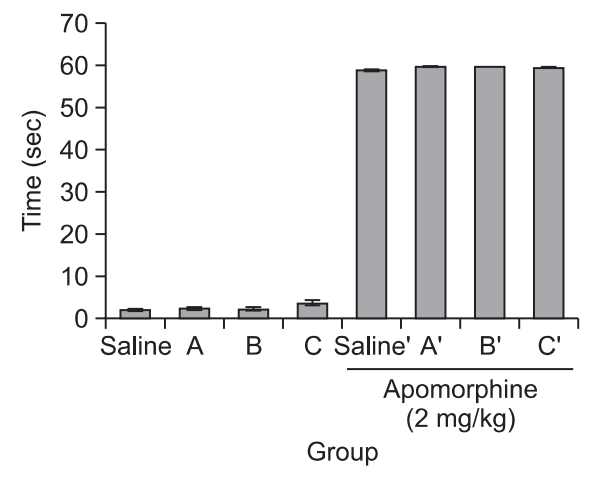

Fig. 1. Climbing behaviors were measured after injection of apomorphine to each subject $(2 \mathrm{mg} / \mathrm{kg}$, subcutaneously). The pretreatments were tramadol $(A(0.03 \mathrm{mg} / \mathrm{kg}), B(0.07 \mathrm{mg} / \mathrm{kg})$ or $C(0.1$ $\mathrm{mg} / \mathrm{kg}$ ), intraperitoneally), administered before the apomorphine treatment (after apomorphine treatment: control', A' (0.03 mg/kg), B' $(0.07 \mathrm{mg} / \mathrm{kg}), C^{\prime}(0.1 \mathrm{mg} / \mathrm{kg})$, i.p.). Data are mean \pm standard error $(n=15)$.

Self-administration test: Surgical procedures were as follows. The rats were anesthetized with pentobarbital sodium (Entobar ${ }^{\circledR}$, Hanlim Pharmaceuticals, Seoul, South Korea). The surgical procedures adhered to aseptic conditions as described previously (Weeks, 1972; Mucha et al., 1982). Briefly, a catheter was inserted into the right jugular vein and catheter exited on the shoulder. The rats received heparin everyday during the experimental periods. After surgery, each rat recovered for at least 14 days in a controlled cage, receiving a solid diet and tap water ad libitum.

Testing procedures were as follows. The rats could self-administer one of the three doses of tramadol $(0.3,0.7$, and 1.5 $\mathrm{mg} / \mathrm{kg} / 0.1 \mathrm{ml}$ per infusion), and a negative control substance (saline, $0.1 \mathrm{ml}$ per infusion) for $6 \mathrm{~s}$ followed by $20 \mathrm{~s}$ of time-out, during daily $2 \mathrm{~h}$ sessions on a fixed-ratio 1 (FR1) reinforcement schedule. On this schedule, when a rat pressed the active lever, it received a certain drug dose $(0.1 \mathrm{ml})$ injected into the jugular vein through the catheter. The self-administration chamber contained two levers linked to a computer program that recorded the experimental data. The test was carried out for $>7$ days.

Statistics: Data are expressed as mean \pm standard error. The climbing, jumping, and head twitch data were analyzed via paired $t$-tests. Paired $t$-tests were also used to analyze the CPP and self-administration data $(p<0.05)$.

\section{RESULTS}

\section{Climbing behavior test}

We measured climbing behavior in the experimental mice with or without pre-treatment of the saline $(1 \mathrm{mg} / \mathrm{kg}$, i.p.) or tramadol $(0.03,0.07$, or $0.1 \mathrm{mg} / \mathrm{kg}$, i.p.) to determine whether tramadol affects the dopaminergic system. No differences were observed between the saline treated group and the tramadol treated groups, regardless of drug concentration with or without apomorphine treatment (Fig. 1).

\section{Jumping behavior test}

The jumping test was performed to determine if tramadol showed withdrawal syndrome. We administered the saline

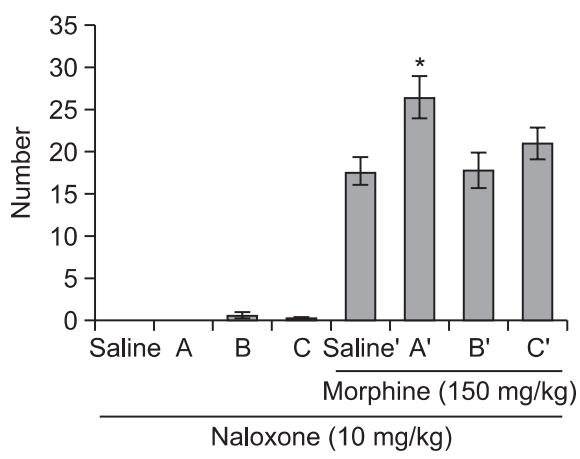

Fig. 2. Tramadol $(A(0.03 \mathrm{mg} / \mathrm{kg})$, B $(0.07 \mathrm{mg} / \mathrm{kg})$ or $C(0.1 \mathrm{mg} / \mathrm{kg})$, intraperitoneally [i.p.]) was administered prior to morphine administration. Morphine (150 mg/kg, subcutaneously) was administered $4 \mathrm{hr}$ prior to naloxone administration (after morphine treatment: control', A' (0.03 mg/kg), B' (0.07 mg/kg), C' (0.1 mg/kg), i.p.). The jumping score in groups $(n=15)$ was measured for 15 min immediately after injection of naloxone $(10 \mathrm{mg} / \mathrm{kg}$, i.p.). Each value is mean \pm standard error. ${ }^{*}<0.05$ compared with saline treated group.

(1 $\mathrm{mg} / \mathrm{kg}$, i.p.) or one of three doses of tramadol $(0.03,0.07$, or $0.1 \mathrm{mg} / \mathrm{kg}$, i.p.) prior to administering morphine. The mice received morphine (150 mg/kg, subcutaneously) $4 \mathrm{hr}$ before naloxone $(10 \mathrm{mg} / \mathrm{kg}$, i.p.). As shown in Fig. 2, two groups of tramadol-treated mice $(0.03$ and $0.07 \mathrm{mg} / \mathrm{kg})$ showed the jumping behavior, but the difference between the salinetreated group and tramadol-treated group was not significant. In the morphine-pretreated groups, two of tramadol-treated groups jumped more than saline-treated group; one tramadoltreated group showed a statistically significant increase $(0.03$ $\mathrm{mg} / \mathrm{kg}$ ). The results are depicted in Fig. 2.

\section{Head twitch response}

The head twitch response was observed to evaluate the serotonergic effect of tramadol. One of the three doses of tramadol $(0.01,0.03$, or $0.07 \mathrm{mg} / \mathrm{kg}$, i.p.) was administered prior to administering serotonin (5-HT, 3-4 mg/kg, i.c.v.). We counted responses in each of the groups three times, for 2 min each, with 10 min intervals. As shown in Fig. 3, no mice in either the saline-treated group or the tramadol treated groups showed a head twitch response in the absence of serotonin. In contrast, the tramadol-treated groups showed a tendency for increasing responses compared with that in the saline-treated group. However, only one tramadol-treated group $(0.07 \mathrm{mg} /$ kg) showed a significant increase (Fig. 3).

\section{Conditioned place preference}

The possibility for psychological dependency or abuse liability was evaluated through conditioned place preference and self-administration. Considering the overall results, the animal's place preference clearly changed in every group during the 8 day-conditioning period. In contrast with the mice treated with saline, the entire group treated with drugs (tramadol and methamphetamine) spent more time in the undesirable room after the conditioning period. When the differences were compared between the saline-treated and drug-treated groups, the animals that received tramadol showed a dose-dependent pattern and significant place preference scores (Fig. 4).

\section{Self-administration}

The self-administration test was maintained on a FR 1 


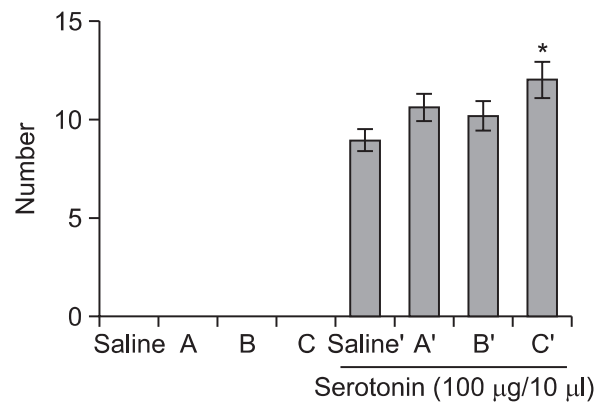

Fig. 3. Tramadol (A $(0.01 \mathrm{mg} / \mathrm{kg})$, B $(0.03 \mathrm{mg} / \mathrm{kg})$ or $C(0.07 \mathrm{mg} /$ $\mathrm{kg})$, i.p.) was injected prior to serotonin $(5-\mathrm{HT}, 3-4 \mathrm{mg} / \mathrm{kg}$, intracerebroventricularly) administration (after serotonin treatment: control', A' (0.01 mg/kg), B' (0.03 mg/kg), C' (0.07 mg/kg), i.p.). The response scores in the groups $(n=14)$ were measured for $2 \mathrm{~min}$, three times at 10 min of intervals. Each value is mean \pm standard error. ${ }^{*} p<0.05$ compared with saline treated group.

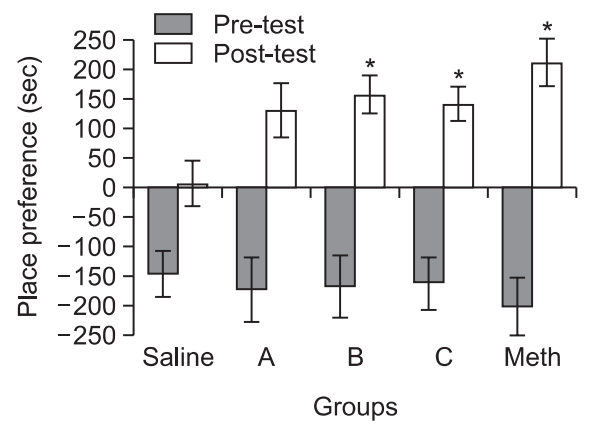

Fig. 4. Mice were preconditioned for 2 days without drug treatment. Then tramadol (A $(0.5 \mathrm{mg} / \mathrm{kg}), B(1.47 \mathrm{mg} / \mathrm{kg})$ or C $(2.94 \mathrm{mg} /$ $\mathrm{kg})$, intraperitoneally [i.p.]), saline ((-) control, $1 \mathrm{ml}$, i.p.) and methamphetamine $((+)$ control, $1 \mathrm{mg} / \mathrm{kg}$, i.p.) were administered to the mice once every other day for 8 days. Place preference was measured the next day after the conditioning period. Data are mean \pm standard error $(n=10) .{ }^{*} p<0.05$, compared with saline treated group.

schedule for $>7$ days, and the responses on the active lever were checked on a daily basis. The saline-treated group did not show active responses. Interestingly, the experimental rats in all three tramadol-treated groups showed increased selfadministration and significant active responses compared with those of the saline-treated group (Fig. 5).

\section{DISCUSSION}

Tramadol is structurally related with opioids such as morphine and codeine and has an analgesic effect. It is commonly used to treat patients with moderate to severe pain due to critical surgery. However, its abuse liability and dependence potential have not been well discussed. We performed various animal behavioral experiments to demonstrate the mode of action and the potential for inducing physical or psychological dependence of tramadol. Climbing behavior and head twitch experiments were performed as pre-evaluating experiments to determine whether tramadol affected the dopaminergic and serotonergic systems. Tramadol did not induce any significant change in animal behavior in the climbing behavior experi-

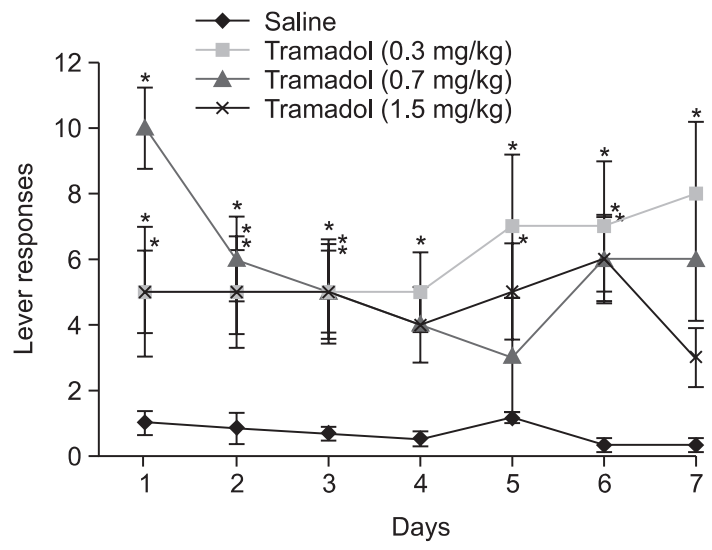

Fig. 5. The animals were administered tramadol (at $0.3,0.7$ or $1.5 \mathrm{mg} / \mathrm{kg} / 0.1 \mathrm{ml}$ per infusion) for $6 \mathrm{sec}$ followed by a $20 \mathrm{sec}$ timeout period in the way of self-administration. Lever responses were performed everyday for more than 7 days. Data are expressed as mean \pm standard error ( $n=6$ or 8 ), and the t-test was used for statistical analysis $\left({ }^{*} p<0.05\right.$ as compared with the saline treated group).

ment, whereas one dose of tramadol significantly increased head-twitch behavior. These results were concurred with previous reports that the activity of tramadol is mediated both by activating and modulating the serotonergic system (Zhang et al., 2012). Also, there are many reports on tramadol's serotonin syndrome (Mansouripour and Afshari, 2013; Park et al., 2014). Since the serotonin syndrome of tramadol has been noticed through several case reports only, the modes of action need to be revealed through further molecular studies. The jumping test result suggested that tramadol may induce physical dependence when morphine was pre-treated. Studies have commonly noted that withdrawal of jumping behavior is the most reliable and generally useful for measuring physical dependence in rodents, particularly with regard to opioids (Way et al., 1969; Saelens et al., 1971; Smits, 1975; Ritzmann, 1981; El-Kadi and Sharif, 1994; Kest et al., 2001). Additional research will be needed to confirm physical dependence of tramadol.

The conditioned place preference test and self-administration test were performed to evaluate the psychological dependence potential of tramadol. Mice that stayed longer in the black chamber during the preconditioning phase of the conditioned place preference test were selected for the experiment. Significantly meaningful and dose-dependent data were obtained in the tramadol administered group. Moreover, significant increases in self-administration were observed in all groups of tramadol-treated rats. In this experiment, the experimental rats in all the three groups of tramadol acquired self-administration and demonstrated significant active responses compared with those of the negative control (salinetreated) group. Based on these results, it seems clear that tramadol has potential for causing psychological dependence in rodents.

Several studies have focused on the dependence potential and/or abuse liability of tramadol as well as the drug's clinical benefits in case reports (Sarkar et al., 2012; Nebhinani et al., 2013; Zhang and Liu, 2013; Randall and Crane, 2014). One report showed that tramadol induces conditioned place preference in rats based on its interactions with morphine and 
buprenorphine (Zhang et al., 2012). Taken together the results from various animal behavioral tests including conditioned place preference and self-administration tests, we conclude that tramadol might have a potential to induce physical and psychological dependence in rodents. This result suggests that it would be worthwhile monitoring usage of tramadol to prevent possible drug abuse in the future.

\section{ACKNOWLEGMENTS}

This study was supported by the National Institute of Food and Drug Safety Evaluation (09171KFDA667).

\section{REFERENCES}

Acheson, S. K., Richardson, R. and Swarzwelder, H. S. (1999) Developmental changes in seizure susceptibility during ethanol withdrawal. Alcohol 18, 23-26.

Bozarth, M. A. (1987) Conditioned place preference: a parametric analysis using system heroin injection. In Methods of Assessing the Reinforcing Properties of Abused Drugs (Michael A. Bozarth, ED), pp241-273. Springer, New York.

Chung, C. S., Wang, J., Wehman, M. and Rhoads, D. E. (2008) Severity of alcohol withdrawal symptoms depends on developmental stage of Long-Evans rats. Pharmacol. Biochem. Behav. 89, 137144.

Doremus, T. L., Brunell, S. C., Varlinskaya, E. L. and Spear, L. P. (2003) Anxiogenic effects during withdrawal from acute ethanol in adolescent and adult rats. Pharmacol. Biochem. Behav. 75, 411418.

El-Kadi, A. O. and Sharif, S. I. (1994) The influence of various experimental conditions on the expression of naloxone-induced withdrawal symptoms in mice. Gen. Pharmacol. 25, 1505-1510.

Gorelick, D. A., Gardner, E. L. and Xi, Z. X. (2004) Agents in development for the management of cocaine abuse. Drugs 64, 1547-1573.

Kest, B., Palmese, C. A., Hopkins, E., Adler, M. and Juni, A. (2001) Assessment of acute and chronic morphine dependence in male and female mice. Pharmacol. Biochem. Behav. 70, 149-156.

Koob, G. F. (1999) Drug addiction: the yin and yang of hedonic homeostasis. Neuron 16, 893-896.

Koob, G. F. (1992) Drugs of abuse: anatomy, pharmacology and function of reward pathways. Trends Pharmacol. Sci. 13, 177-184.

Landry, M. J., Smith, D. E., McDuff, D. R. and Baghman, O. L. (1992) Benzodiazepine dependence and withdrawal: identification and medical management. J. Am. Board Fam. Pract. 5, 167-175.

Mansouripour, S. M. and Afshari, R. (2013) Chlordiazepoxide preventive effect on tramadol overdose induced serotonin syndrome evaluated by hunter and radsmski criteria: a clinical trial. Toxicol Intern. 20, 126-131.

Morris, S. A., Kelso, M. L., Liput, D. J., Mrshall, K. and Nixon (2010) Similar withdrawal severity in adolescents and adults in a rat model of alcohol dependence. Alcohol 44, 89-98.

Mucha, R. F., van der Kooy, D., O'Shaughnessy, M. and Bucenieks, P. (1982) Drug reinforcement studied by the use of place conditioning in rat. Brain Res. 243, 91-105.

Narita, M., Akai, H., Nagumo, Y., Sunagawa, N., Hasebe, K., Nagase, H., Kita, T., Hara, C. and Suzuki, T. (2004) Implications of protein kinase $\mathrm{C}$ in the nucleus accumbens in the development of sensitization to methamphetamine in rats. Neuroscience 127, 941-948.

Nebhinani, N., Singh, S. M. and Gupta, G. (2013) A patient with tramadol dependence and predictable provoked epileptic seizures. Indian J. Psychiatry 55, 293-294.

Park, S. H., Wackernuh, R. C. and Stimmel, G. L. (2014) Serotonin syndrome: is it a reason to avoid the use of tramadol with antidepressans? J. Pharm. Prac. 27, 71-78.

Randall, C. and Crane, J. (2014) Tramadol deaths in northern Ireland: a review of cases from 1996 to 2012. J. Forensic Leg. Med. 23 32-36.

Ritzmann, R. F. (1981) Opiate dependence following acute injections of morphine and naloxone: the assessment of various withdrawal signs. Pharmacol. Biochem. Behav. 14, 575-577.

Saelens, J. K., Granat, F. R. and Sawyer, W. K. (1971) The mouse jumping test-a simple screening method to estimate the physical dependence capacity of analgesics. Arch. Int. Pharmacodyn. Ther 190, 213-218.

Sarkar, S., Nebhinani, N., Singh, S. M., Mattoo, S. K. and Basu, D. (2012) Tramadol dependence: a case series from India. Indian J. Psychol. Med. 34, 283-285.

Smits, S. E. (1975) Quantitation of physical dependence in mice by naloxone-precipitated jumping after a single dose of morphine. Res. Commun. Chem. Pathol. Pharmacol. 10, 651-661.

Taylor, C. Z. (2002) Religious addiction: obsession with spirituality. Pastor. Psychology 50, 291-315.

Varlinskaya, E. I. and Spear, L. P. (2002) Acute effects of ethanol on social behavior of adolescent and adult rats: role of familiarity of the test situation. Alcohol Clin. Exp. Res. 26, 1502-1511.

Way, E. L., Loh, H. H. and Shen, F. H. (1969) Simultaneous quantitative assessment of morphine tolerance and physical dependence. J. Pharmacol. Exp. Ther. 167, 1-8.

Weeks, J. R. (1972) Long term intraveneous infusion (R. D. Myers, Ed.), pp.155-168. Academic press, New York.

Zhang, M., Jing, L., Liu, Q., Wen, R. T., Li, J. X., Li, Y. L., Gong, Q. and Liang, J. H. (2012) Tramadol induces conditioned place preference in rats: interactions with morphine and buprenorphine. Neuroscience Lett. 520, 87-91.

Zhang, H. and Liu, Z. (2013) The investigation of tramadol dependence with no history of substance abuse: a cross-sectional survey of spontaneously reported cases in Guangzhou city, China. Biomed. Res. Int. 2013, 283425. 